\title{
As contribuições de Werner Markert para a produção acadêmica e científica da área de trabalho e educação no Brasil
}

Entrevistadora: Francisca Rejane Bezerra Andrade

Universidade Estadual do Ceará

\section{Apresentação}

Em 2 de março de 2008, faleceu o Prof. Dr. Werner Markert, pesquisador alemão do Bundesinstitut für Berufsbildung - BIBB (Instituto Federal de Educação Profissional) e da Johann Wolfgang Goethe Universität Frankfurt (Universidade de Frankfurt). No Brasil, ele atuou como pesquisador visitante na Universidade do Rio de Janeiro (1990-1995), na Universidade Federal do Rio Grande do Norte (19992003) e na Universidade Federal do Ceará (20052007). Sua trajetória foi marcada por significativas contribuições acadêmicas e científicas nas áreas de trabalho e educação e sociologia do trabalho, tanto na Alemanha quanto no Brasil. No dia 9 de novembro de 2011, o Prof. Dr. Werner Markert completaria 70 anos, fato que instigou a socialização da presente entrevista com os cientistas brasileiros. A entrevista foi realizada em 6 de agosto de 1996, durante visita ao BIBB, na Alemanha, e versou sobre as transformações no mundo do trabalho e seus impactos para a educação profissional na Alemanha e no Brasil. 


\section{Introdução}

Nos anos 1980, intensificaram-se os debates em torno das relações entre educação e trabalho. Ao chegarmos no início da segunda década do século XXI, identificamos diferentes concepções teóricas que buscam analisar as transformações ocorridas em tais relações, contribuindo para uma significativa produção científica na área.

0 Prof. Dr. Werner Markert teve papel relevante nesse processo ao publicar as obras Teorias de educação do Iluminismo, conceitos de trabalho e do sujeito (1994), Trabalho, qualificação e politecnia (1996), Formação profissional no Brasil (1997) e Trabalho, comunicação e competência: contribuições para a construção crítica de um conceito e para a formação do profissional transformativo (2004), bem como ao publicar diversos artigos em revistas nacionais e internacionais das áreas de trabalho e educação e sociologia do trabalho entre as décadas de 1980 e 2000.

Suas produções apresentam análises sobre mudanças no sistema de trabalho, na produção e no serviço resultantes de um conjunto de transformações ocorridas nos anos 1970, nos países considerados avançados, e, posteriormente, no final da década de 1980, nos países ditos em desenvolvimento. Tais transformações, de acordo com ele, afetaram significativamente o capitalismo e o sistema de produção de mercadorias.

Destacamos que essa reconfiguração econômica provocou o desenvolvimento de estratégias e comportamentos, resultando em uma combinação de competição e cooperação mundial entre empresas e países, bem como na disseminação de novos conceitos de produção.

É a partir desse momento que novos processos produtivos mesclam-se com o taylorismo e com o fordismo, ou até mesmo os substituem, em várias regiões do mundo. A produção em massa e o cronômetro perdem espaço para a produção flexível, também denominada produ- ção japonesa ou enxuta. Esse processo provocou intensas modificações, tanto na estrutura produtiva quanto na classe trabalhadora.

Partindo do exposto, pode-se dizer que as análises empreendidas pelo Prof. Dr. Werner Markert nesta entrevista são relevantes para compreendermos o processo ainda presente de introdução de novos mecanismos e modos de acumulação e reprodução do capital, integrados à expansão do neoliberalismo.

Em síntese, continuamos a presenciar um amplo processo de mudança no mercado de trabalho que destaca a qualificação como estando cada vez mais relacionada ao grau de escolaridade dos trabalhadores, fazendo com que aqueles que não tenham concluído, no mínimo, uma educação básica tenham poucas chances de continuar ou ingressar nos setores mais avançados da economia, bem como em um trabalho formal e decente.

Um dos grandes desafios enfrentados pela sociedade brasileira na atualidade é exatamente o referente à escolaridade da população, pois as demandas por mão de obra qualificada, polivalente e cooperativa são a base da gestão organizacional das empresas reestruturadas. Em contraponto, há ainda hoje no país um grande contingente de analfabetos e semianalfabetos. Sabe-se que essa população tem poucas chances de ingressar ou permanecer no mercado de trabalho formal reestruturado. Sabe-se, ainda, que esse problema não poderá ser solucionado somente por meio de programas educacionais pontuais e focalizados, mas necessita, essencialmente, do desenvolvimento de uma educação de qualidade para todos. Essas e outras questões estão presentes na discussão que o Prof. Dr. Werner Markert realiza na presente entrevista.

\section{Entrevista com o Prof. Dr. Werner Markert}

Prof. Werner, o que caracteriza a introdução de novos conceitos de produção na empresa no final deste século? 
Nós podemos indicar alguns elementos que caracterizam os novos conceitos de produção. Antes disso, acho importante destacar que esses novos conceitos são orientados pelas mudanças das estruturas de trabalho. Os elementos seriam: primeiro, a introdução de princípios de mercado nas estratégias empresariais de produção do trabalho; o segundo critério é a descentralização dos processos de decisão a nível empresarial; um terceiro critério é a diminuição das hierarquias na produção (por exemplo, na Toyota, empresa japonesa, existem atualmente apenas três níveis de organização, em vez de cinco ou até mais níveis presentes na estrutura de produção fordista); um quarto critério é a busca por uma forma de gerenciamento consensual; um quinto critério é a existência do trabalho em grupos.

Como o senhor analisa o desenvolvimento dos novos conceitos de produção na Alemanha e no Brasil?

Certamente, não existe a implantação de um novo conceito de produção só na Alemanha ou só no Brasil. Isso depende muito da situação tecnológica empresarial, da relação do empresariado com os sindicatos, das leis sociais, da qualificação dos trabalhadores. Nós temos que considerar essas diferenças ao discutirmos as consequências da implantação dos novos conceitos para o desenvolvimento industrial de um país.

Eu identifiquei, por meio da literatura existente, algumas características que, por exemplo, definem a situação na empresa brasileira, características estas que evitam o desenvolvimento de um conceito participativo a partir da introdução dos novos conceitos de produção, em oposição à realidade da Alemanha, onde a força dos sindicatos favorece mais um tipo de conceito participativo. Essas características negativas no Brasil são as seguintes:

1) Não há, em geral, nenhuma indução para a participação dos empregados nas decisões relacionadas à racionalização nas empresas brasileiras.

2) Existem grandes diferenças salariais e de status na empresa brasileira. É a maior diferença salarial a nivel mundial. Essa diferença entre os salários na empresa brasileira evita a introdução de uma hierarquia descentralizada.

3) 0 controle da qualidade é organizado de forma centralizada e não participativa.

4) Existe uma insuficiente oferta de aperfeiçoamento para os trabalhadores na empresa.

5) Existe um elevado nível de especialização na organização do trabalho.

6) Não existe nenhuma indução para uma atuação mais representativa dos sindicatos nos conselhos das empresas com vistas à participação nas decisões empresarias.

Se compararmos essas características com a Alemanha, lá, em geral, nós temos, por lei, uma forte participação dos sindicatos nas decisões empresariais. Existe uma forma de cogestão. Isso não significa que as decisões empresariais não são centralizadas, mas a lógica da implantação desses novos conceitos implica certa participação dos trabalhadores nas decisões. 0 raciocínio leva ao entendimento de que uma mudança conceitual na produção, nas estruturas do trabalho, e a implantação de novos pacotes tecnológicos funcionam bem melhor se os trabalhadores conhecerem esse processo, forem nele incluídos e até receberem continuamente um aperfeiçoamento. Esse aspecto pode ser caracterizado como uma diferença entre os sistemas no Brasil e na Alemanha.

Prof. Werner, quais são os impactos desse processo para os trabalhadores?

Primeiro, nós não podemos esquecer as consequências negativas da introdução dos novos conceitos de produção. Falaremos sobre isso depois. Já quero mencionar aqui a perda de vagas na produção industrial; mas quem tem a chance e a sorte de continuar a trabalhar nesse novo tipo de empresa deve encontrar 
certas vantagens em relação à sua situação no trabalho ou em sua vida social. A situação no trabalho deve melhorar e o novo trabalho deve ser menos rotinizado do que no sistema taylorista-fordista. Nós encontramos maiores responsabilidade e autonomia dos trabalhadores no processo de trabalho, uma diminuição dos níveis hierárquicos entre os trabalhadores, uma maior qualificação e um nível mais alto nos salários daqueles que continuam no processo. Percebo que as consequências sociais para eles também são melhores.

Para o senhor, quais seriam as consequências dessas mudanças no mundo do trabalho para a educação alemã e brasileira?

Considerando a continuação da implantação desses novos conceitos, podemos imaginar uma ampliação da educação para a sociedade do futuro. Por outro lado, considerando que encontramos continuamente menos postos de trabalho, o resultado pode ser uma cisão no sistema educacional, que deve oferecer sistemas de formação profissional e de aperfeiçoamento para os privilegiados e piorar as ofertas para aqueles que não terão a chance de ingressar nesse novo tipo de trabalho.

Nós sabemos, por exemplo, que a criação de novos empregos nos Estados Unidos surge em grande número no setor de serviços, mas com um nível de qualificação muito baixo, o que não tem nada haver com as demandas por autonomia e responsabilidade para aqueles que ocupam empregos privilegiados na indústria.

Percebe-se uma tendência de melhorar a formação e de aumentar as ofertas para uma boa educação, mas, provavelmente, dentro do sistema capitalista, tais ofertas devem estar separadas do sistema educacional geral. Esse é um grande perigo. Nós encontramos esse perigo em países como Chile, Argentina e Brasil. Na Alemanha, ainda não há essa cisão no sistema educacional, mas eu vejo que a estrutura, a filosofia ou o conceito de uma educação para a igualdade devem ser ameaçados também na Alemanha e nos Estados economicamente desenvolvidos.

O senhor poderia traçar um paralelo entre a redução dos postos de trabalho nas empresas e a atuação sindical na atualidade?

Primeiro, nós encontramos, na implantação desse novo conceito de produção, em todos os países e em todos os sistemas econômicos, uma redução dos postos de trabalho. Essa é uma tendência mundial. A consequência é o desaparecimento dos postos, em geral, no setor industrial. 0 fator positivo é que também desaparecem os postos com menor qualificação e aumentam, na empresa, os postos de maior qualificação. No entanto, é importante observar que tal aumento não compensa a redução dos cargos em geral. Essa é a consequência social. A atuação sindical nacional perde sempre mais influência, porque perde membros. Na Alemanha, os grandes sindicatos perderam milhões de membros nos últimos anos devido a demissões, e aqueles que continuam sentem-se como privilegiados; questiona-se se eles ainda têm interesse em organizarem-se num sindicato. Infelizmente, os sindicatos ainda não têm conceitos para combater essas tendências ou até para definir um novo conceito de produção. Esse é um grande fator negativo da esquerda mundial.

Prof. Werner, que análise o senhor faz da participação dos trabalhadores nessa nova realidade empresarial?

A participação dos trabalhadores ocorre sempre dentro do processo de produção. 0 que há é uma participação em termos mais técnicos e menos em termos de uma participação ativa nas decisões sobre os investimentos e sobre a racionalização.

A diminuição da hierarquia dentro da empresa equivale a uma maior participação daqueles que continuam e que têm uma maior qualifıcação, mas isso não significa que esteja 
ocorrendo uma participação qualitativa, de cogestão. 0 que se amplia é a participação técnica no processo, mas não há uma participação nas decisões econômicas e políticas da empresa.

Como podemos caracterizar essa participação técnica? Quais seriam as principais competências desenvolvidas pelos novos modelos de formação profissional na Alemanha?

As demandas são orientadas por aquele conceito que já apresentei várias vezes em minhas contribuições. Citarei um artigo que foi publicado na revista Educação e Sociedade, em que desenvolvi alguns aspectos referentes às qualificações-chave. Com certeza, nós encontramos uma ampliação dessas qualificações-chave nas empresas, e essa ampliação tem consequências para a formação profissional também na Alemanha. A orientação para a formação é voltada menos para a especialização e orientada mais pelas competências de análise: competências metodológicas, competências sociais, competências comunicativas. Com isso, inicia-se, na Alemanha, uma crítica ao modelo do sistema dual de formação profissional. 0 raciocínio e a discussão indicam que seria melhor orientar a formação profissional também na Alemanha para uma formação mais geral e menos técnica. Ainda não há respostas a essa discussão, mas uma maior oferta de competências gerais no ensino médio parece oferecer mais possibilidades de que os jovens adaptem-se às novas condições da produção do que um sistema profissional ainda orientado pelas competências técnicas. Mas isso é uma tendência, e depende muito do sistema, da formação. Nós temos, na Alemanha, uma reorganização da formação profissional especialmente no setor industrial, mas também no setor químico e no setor de serviços, como bancos, escritórios. Então, o sistema profissional alemão já reagiu oferecendo novos currículos na formação profissional para certas profissões, mas a tendência deve ser uma ampliação da educação geral no ensino médio.
O que o senhor identifica como inovador no desenvolvimento de habilidades do trabalhador na empresa flexibilizada?

As novas habilidades são caracterizadas pelas mudanças internas dos conceitos de produção. Podemos defınir brevemente alguns conceitos centrais que influenciaram os novos currículos na Alemanha para certos profissionais, especialmente para as profissões do setor industrial. São eles: o conceito das qualificações-chave; os conceitos de habilidades como uma orientação das competências na ampliação de tarefas e de enriquecimento do trabalho, em vez do tradicional processo do trabalho especializado; uma maior chance de o pessoal introduzir novas experiências; iniciativas no planejamento dos processos de decisão no ambiente do trabalho; uma maior cogestão no local do trabalho; uma tendência de ampliar as tarefas e de integrar os trabalhadores nas decisões sobre mudanças técnicas; e uma maior flexibilidade na execução de cargos.

\section{E, no Brasil, como o senhor analisa essa possibilidade?}

Já caracterizei alguns pontos críticos nas estruturas das empresas brasileiras. Eu gostaria ainda de dizer que todas as pesquisas mostram que a intenção do empresário tradicional brasileiro ou do gerente tradicional brasileiro é continuar com o sistema de formação e da política empresarial que prima pela não participação. Implantam-se novos pacotes tecnológicos, realiza-se um treinamento rápido e pressiona-se o pessoal a aceitar e reagir àquelas mudanças, ou seja, desenvolve-se um sistema autocrático.

Até o SENAI tem de mudar seu conceito de formação, tem de oferecer novos conceitos de formação profissional, não mais aquele antigo tipo de especializar no primeiro ano e depois oferecer um semiqualificado a empresa. As demandas das empresas mudam continuamente, e parece que a política empresarial em relação ao pessoal passa a exigir um novo perfil 
de trabalhador e certamente irá implantar, no futuro, um novo tipo de gerenciamento: menos autocrático, menos hierarquizado, trazendo como consequência a possibilidade de essas empresas aceitarem e formarem também um novo tipo de operário responsável e qualificado.

Que demandas o Instituto Federal de Educação Profissional (BIBB) tem recebido para desenvolver novos projetos na área de formação profissional na Alemanha?

0 BIBB foi o instituto responsável por desenvolver, juntamente com as empresas e com os sindicatos, os novos conceitos de formação profissional em vários setores, começando já nos anos 1980, primeiramente, com o setor industrial. As próprias empresas identificaram a necessidade de uma mudança do treinamento clássico e tradicional. Essa realidade mudou significativamente e hoje quase não existe nenhum setor na economia alemã que não reconhece tal mudança. Por isso, o BIBB foi altamente envolvido nesse processo de desenvolvimento de novos currículos, em quase todos os setores da formação dos jovens e também no desenvolvimento de novos conceitos de aperfeiçoamento para aqueles que receberam apenas uma formação tradicional quando eram jovens. Entende-se que esses profissionais precisam receber um aperfeiçoamento para aprender novas qualificações e competências.

Qual tem sido seu objeto de estudo na atualidade?

Estou especialmente envolvido na análise do conceito de competências e no desenvolvimento de conceitos de aperfeiçoamento para aqueles grupos de adultos que agora estão implicados no processo de mudanças no trabalho. Participo de três projetos nesta área. Primeiro, estamos analisando as consequências da implantação do trabalho em grupo em pequenas e médias empresas. Identificamos, na pesquisa, que os trabalhadores tradicionais têm grandes dificuldades em adaptarem-se a esse novo tipo de trabalho em grupo, em termos de serem mais responsáveis pelo seu próprio planejamento de trabalho. Eles nunca foram capazes de planejar seus trabalhos junto com os seus colegas. Geralmente, o supervisor vinha no início da jornada e depositava o plano de trabalho para cada trabalhador; eles então tinham de executar as tarefas e, quando terminavam, recebiam um novo plano. Mas agora, no trabalho em grupo, é importante conhecer quase a totalidade do processo da produção, a começar pela identificação das peças necessárias, pela colaboração com os colegas que trabalham no próprio ambiente de trabalho, pela decisão conjunta sobre quem vai executar as atividades necessárias. 0 trabalhador é responsável pela qualidade da produção; é responsável também por observar como está o desempenho da máquina, e não mais recebe suas tarefas de uma maneira autoritária. Ele tem de entender como organizar seu trabalho em grupo e junto com outros departamentos da empresa para satisfazer as diversas demandas e ofertas que a empresa tem naquele momento, nos dias seguintes e nas semanas seguintes. Ele tem de pensar sobre como pode cumprir, por exemplo, as datas definidas para terminar a produção de certas peças ou de certo produto. Ele faz parte desse planejamento e tem de entendê-lo, tem de ser flexível dentro dele, tem de comunicar-se em termos de organização do trabalho, de divisão do trabalho no grupo e com os outros grupos da empresa, por exemplo, com a montagem, com o técnico, tudo isso. Então, essas novas demandas não revelam a necessidade apenas de qualificações técnicas; certamente, o trabalhador tem de ser capaz de entender um programa computadorizado, tem de poder ler informações que vêm daquele sistema de produção computadorizado, mas isso não é a única novidade. 0 maior problema é ele ser capaz de realizar essa nova organização do trabalho em conjunto, em grupo.

O segundo projeto volta-se para uma pesquisa sobre as novas relações entre empresa e fornecedor. Por isso, nós temos o maior interesse em cooperar com pesquisadores brasileiros que 
conhecem o planejamento das novas empresas da Volkswagen, em Resende, e da Mercedes-Benz, em Juiz de Fora. Um colega do SENAI nos ofereceu uma possibilidade de ter acesso a essas empresas para podermos pesquisar sobre esses novos tipos de relacionamento, os quais têm consequências também para a qualificação do envolvidos, dos trabalhadores na empresa e dos fornecedores, que terão uma enorme ampliação de suas tarefas, de suas responsabilidades. Esse novo modelo só pode ser implantado numa empresa que for construída do zero; ele não é possível num sistema que já funciona. Isso não pode acontecer de hoje para amanhã, por exemplo, na Alemanha. Só pode acontecer numa situação em que é possivel começar do ponto zero, como é feito naquelas empresas novas da Volkswagen e da Mercedes-Benz no Brasil.

0 terceiro projeto é um projeto europeu que objetiva desenvolver conceitos para novos tipos de qualidade certificada por meio do ISO 9000. Tal projeto pretende, primeiramente, analisar as mudanças ocorridas dentro da organização social das empresas que querem ou já têm a certificação. Isso também deve ser uma questão importante para o Brasil: as mudanças que são necessárias com a instalação de uma qualidade certificada no setor organizacional.

$O$ senhor poderia falar sobre os projetos de educação profissional desenvolvidos pelo BIBB que estão relacionados ao desemprego?

Infelizmente, a formação não pode resolver o problema da falta de novos postos de trabalho, mas o governo pediu ao BIBB para ajudar nesse campo. 0 plano é pesquisar e definir novos espaços ocupacionais, que podem ser novos campos de trabalho no futuro, fora do sistema industrial, porque o governo alemão sabe que o setor industrial não será mais o setor principal de desenvolvimento para a Alemanha nos próximos 20, 50 anos. Então, são realizados diversos projetos com recursos suficientes que buscam responder às questões: para onde vão as mudanças no setor industrial?; podemos identificar novos campos de ocupação naqueles setores industriais?

Nós perdemos empregos na produção direta, mas, aparentemente, surgem novos tipos de ocupação no campo da organização dos serviços, de marketing, e as pessoas que irão atuar nesses espaços ocupacionais também precisam de conhecimentos técnicos.

0 governo definiu, ainda, um grande projeto nacional no setor de serviços para identificar as novas demandas e os novos espaços ocupacionais desse setor. A tarefa do BIBB é desenvolver currículos para essas novas áreas.

Em sua opinião, qual deveria ser a preocupação central dos pesquisadores brasileiros que atuam na área de educação profissional?

Essa é uma questão muito ampla, e eu posso identificar o que considero como lacuna. Quando observo as pesquisas e as atividades na área de educação e trabalho nos últimos anos, eu identifico, por exemplo, que não existe uma preocupação em desenvolver novos conceitos para a formação. As pesquisas são altamente particularizadas em setores pequenos, restritos. Falta uma melhor comunicação dos pesquisadores da área de educação com os pesquisadores da sociologia do trabalho, que já apresentam estudos sobre as mudanças ocorridas na produção; por conseguinte, nas pesquisas destes, está ausente o aspecto da educação. Eu acho que falta totalmente a preocupação com conceitos educacionais: como implantar novos conceitos educacionais nas empresas, nas escolas técnicas, conceitos integrados? Isso foi realmente o maior enfoque dos anos 1980 na educação da Alemanha, e eu posso dizer que quase ocorreu uma revolução nos conceitos educacionais da formação profissional alemã relacionados às mudanças nos conceitos de produção. Existe uma enorme necessidade de o Brasil preocupar-se com essa área.

Francisca Rejane Bezerra Andrade é doutora em Educação pela Universidade de São Paulo (2000), com estágio sandwich na Universidade de Frankfurt. Pós-doutora em Ciências da Educação pela Universidade de Frankfurt (2004). Atualmente é professora adjunta da Universidade Estadual do Ceará. 
